\title{
UM RECORTE DA HISTÓRIA DO SOFTWARE LIVRE NO ESTADO BRASILEIRO: UM ESTUDO DE CASO DO PROGRAMA DE SOFTWARE LIVRE DO SERPRO
}

\section{A Cutout of Free Software History in Brazilian State: A Case Study of Serviço Federal de Processamento de Dados (SERPRO)}

\author{
Flávio Gomes da Silva Lisboa* \\ Marilene Zazula Beatriz ${ }^{* * *}$
}

\begin{abstract}
Resumo: Este artigo apresenta resultados de uma pesquisa de mestrado interdisciplinar que buscou compreender como se deu o processo de construção de um software livre por usuários e desenvolvedores de uma empresa estatal brasileira de tecnologia da informação no período de 2003 a 2018, durante o qual vigorou um programa que tinha, entre seus objetivos, o fomento do mercado nacional de software. Como uma das motivações, são apresentados questionamentos sobre a efetividade de projetos estatais de software livre, feitas por Birkinbine (2016), Oram(2016), e representantes do mercado brasileiro de software. Nessa pesquisa, qualitativa, exploratória e descritiva foram utilizados dados primários coletados a partir de um estudo de caso e dados secundários coletados a partir de pesquisa de documentos compilados ou feitos por outros autores. O estudo de caso consistiu de observação direta intensiva pelo instrumento da entrevista. Foram objetos da pesquisa tanto atores humanos (usuários e desenvolvedores) quanto não-humanos (o software selecionado). Para a análise dos resultados foi utilizado o conceito de software livre da Free Software Foundation - FSF e contribuições da Teoria Crítica da Tecnologia de Feenberg(2013). A pesquisa assumiu como premissas a existência de intersecções entre os conjuntos de características do software livre, da economia solidária e da tecnologia social. Nas considerações finais, abordamos contradições encontradas nos discursos favoráveis e contrários à produção de software livre pelo Estado. Os resultados indicaram que entre mais de 800 projetos de software criados pela empresa e classificados por ela como softwares livres, apenas 4 eram softwares livres de acordo com a FSF.
\end{abstract}

Palavras-chave: Economia Solidária. Empresa Estatal. Empresa Pública. Software Livre. Tecnologia Social.

Abstract: This paper presents the results of an interdisciplinary master's research that sought to understand how the process of building free software took place by users and developers of a Brazilian state-owned information technology company between 2003 and 2018, during a

\footnotetext{
Doutorando pelo Programa de Pós-Graduação em Tecnologia e Sociedade da Universidade Tecnológica Federal do Paraná - UTFPR. Mestre em Tecnologia e Sociedade pela UTFPR. https://orcid.org/0000-0002-93967944. PPGTE, UTFPR, Avenida Sete de Setembro, 3165, Curitiba, PR. CEP 80230-901.

** Doutora em Psicologia Social pela Pontifícia Universidade Católica de São Paulo. Mestre em Administração pela Universidade Federal do Paraná. https://orcid.org/0000-0002-8307-7438. PPGTE, UTFPR, Avenida Sete de Setembro, 3165, Curitiba, PR. CEP 80230-901.
} 
state program which had, among its objectives, the promotion of the national software market. As one of the motivations, questions by Birkinbine, Oram, and representatives of the Brazilian software market about the effectiveness of state open source projects are presented. This qualitative, exploratory and descriptive research used primary data collected from a case study and secondary data collected from research of documents compiled or made by other authors. The case study consisted of intensive direct observation by the interview instrument. The subjects of the research were human actors (users and developers) and non-human actors (the selected software). For the analysis of the results the Free Software Foundation - FSF concept of free software and contributions of the Feenberg Critical Theory of Technology were used. The research assumed as premises the existence of intersections between the free software, solidarity economy and social technology feature sets. In the final considerations we approach contradictions found in the discourses in favor and against the production of free software by the state. The results indicated that among more than 800 software projects created by the company and classified by it as free software, only 4 were free software according to the FSF.

Keywords: Free Software. Social Technology. Solidary Economy. State-owned Enterprise.

\section{Introdução}

Segundo Castells (2005), o final do século XX assistiu ao nascimento de uma nova economia, consequência do desenvolvimento de novas tecnologias de informação e comunicação baseadas em inovações das recentes indústrias de eletrônica e computação. Nesse contexto global, durante a presidência de Fernando Henrique Cardoso (1995-2003), foi criado o Programa de Governo Eletrônico do Estado Brasileiro (BRASIL, 2014). Entre as diretrizes desse programa, publicadas em 2002, uma em particular afirmava que o software livre era "recurso estratégico para a implementação do governo eletrônico" e que deveriam ser priorizadas "soluções, programas e serviços baseados em software livre" (BRASIL, 2014).

Software, de acordo com Pressman e Maxim (2016), é um produto que abrange programas (conjuntos de instruções) executáveis em um computador, os conteúdos gerados por eles e descrições de sua estrutura e funcionamento. O termo software livre - do inglês free software - refere-se a um tipo de software cuja forma de licenciamento permite que usuários possam livremente executá-lo, copiá-lo, distribuí-lo, alterá-lo e melhorá-lo (FREE SOFTWARE FOUNDATION, 2001).

A abertura do código-fonte do software, condição necessária para que essas liberdades sejam exercidas, torna a tecnologia de produção de software livre um campo fértil para a prática de um "processo mais democrático no design e no desenvolvimento" dessa tecnologia (FEENBERG, 2013, p. 61), questão que Feenberg aborda em sua Teoria Crítica da Tecnologia.

Lima (2013) relata que

$$
\begin{aligned}
& \text { especificamente no caso brasileiro, o uso de software livre ampliou seu espaço tanto } \\
& \text { nos órgãos públicos, quanto nas empresas, ao expandir a demanda e o mercado a } \\
& \text { partir da criação, em 2003, das Diretrizes da Implementação de Software Livre pelo } \\
& \text { Governo Federal [a qual oficializou a] "opção preferencial do governo por esse tipo } \\
& \text { de software" (LIMA, 2013, p. 76). }
\end{aligned}
$$

O Estado brasileiro não somente usou software livre, como também produziu. O Portal do Software Público Brasileiro, por exemplo, contém resultados de produção estatal de 
software livre (BRASIL, 2019a). Há, entretanto, algumas críticas sobre essa produção. Birkinbine (2016, p. 3893, tradução nossa) afirma que "a efetividade desses projetos e políticas [de software livre dentro de instituições estatais] permanece relativamente inexplorada". De acordo com Milano (2015, p. 144), o movimento de software livre brasileiro - incluindo os agentes estatais, embora muito "ativo politicamente", não é ativo na produção de códigos livres. Ampliando a territorialidade dessa crítica, Oram (2016, p. 6) afirma que os resultados de abertura de código fonte suportada por governos da América Latina são desapontadores.

Seguindo as diretrizes do Programa de Governo Eletrônico do Estado Brasileiro, o Serviço Federal de Processamento de Dados (Serpro) instituiu em 2003 o Programa Serpro de Software Livre - PSSL. O Serpro é uma empresa estatal de tecnologia da informação, criada em 1964 para atender a demanda de automação da arrecadação de tributos do Ministério da Fazenda (atual Ministério da Economia). De acordo com Tiboni (2014), a partir da criação do PSSL, o Serpro deixou de ser apenas um receptor de tecnologias oferecidas por fornecedores e passou a desempenhar o papel de participante ativo no desenvolvimento de soluções livres de tecnologia da informação para o Brasil. Para Tiboni (2014), isso significava que o Serpro passava a ser o principal agente no direcionamento de tecnologia de software para o governo federal.

Compreender o papel efetivo do Serpro como um agente direcionador de tecnologia envolve descobrir se a empresa produziu algum software livre ou apenas usou o que já existia - se agiu como um produtor ou como um consumidor. Cada um desses papéis está relacionado a um modo diferente de apropriação do conhecimento, o saber usar (consumidor) e o saber produzir (produtor). De acordo com a proposta de Adequação Sociotécnica de Dagnino (2014), cada modo de apropriação do conhecimento, por sua vez, está relacionado a um tipo diferente de autonomia. O que apenas usa depende de quem produz, por isso tem menos autonomia. O modo de apropriação de conhecimento tecnológico relaciona-se, assim, à autonomia tecnológica.

A princípio, pode se considerar que a empresa estatal, como parte da estrutura do Estado para provisão de serviços ao cidadão, permitirá que a população se aproprie do conhecimento gerado por ela, ressalvados os casos de segurança estratégica. A inferência que se faz aqui é que o conhecimento da empresa pública deveria ser público, pois a motivação de sua existência é o interesse público. A empresa estatal, entretanto, é ambígua em relação a sua ação, que oscila entre duas faces, pública e privada, conforme afirma Abranches (1979). De acordo com esse autor, interesses microeconômicos, relacionados à manutenção imediata dos negócios da empresa, podem entrar em conflito com o interesse público, citado explicitamente no parágrafo $1^{\circ}$ do artigo $8^{\circ}$ da lei $13.303 / 2016$, que rege as empresas estatais.

Nesse contexto, dentro do qual estamos considerando a produção de software livre dentro de instituições estatais brasileiras de tecnologia da informação, diante de uma presumida dualidade de interesses intrínseca às empresas estatais e considerando também os limites para a realização da pesquisa aqui descrita, a questão principal proposta foi: como se deu a construção de um único e específico software livre por usuários e desenvolvedores do Serviço Federal de Processamento de Dados no período compreendido entre 2003 e 2018 ?

A busca pela resposta a essa questão considerou cinco pressupostos. O primeiro pressuposto é que a comunidade de software livre, organização coletiva que mantém um software livre, tem características em comum com empreendimentos de economia solidária. A economia solidária é uma configuração alternativa ao modo de produção capitalista, cuja materialização é um tipo de organização a qual Gaiger, Kuyven, Ogando, Kappes e Silva (2014, p. 17) referem-se como "empreendimentos econômicos de base coletiva e 
autogestionária". Comunidades de software livre e empreendimentos de economia solidária têm em comum a propriedade coletiva dos bens de produção e a autogestão. O segundo pressuposto é que o software livre tem características em comum com o conceito de tecnologia social de Dagnino (2010). A tecnologia social é uma tecnologia que pode ser adaptada para empresas que têm espaços físicos pequenos e recursos financeiros escassos, ou seja, pequenos empreendimentos. Além disso, ela tem a capacidade de liberar o potencial desses recursos e a criatividade do produtor. Como o software livre pode ser adaptado para empresas pequenas e não possui custo de licenciamento, ele pode ser utilizado como uma tecnologia social. A tecnologia social tem como objetivo principal a inclusão social dos participantes de um empreendimento e não o aumento da produtividade ou da eficiência que é o objetivo principal da tecnologia convencional do modo de produção capitalista. O terceiro pressuposto é que o desenvolvimento de software por uma empresa estatal é orientado pelo modo de produção capitalista. Como consequência, e quarto pressuposto, o software produzido por esse tipo de empresa seria uma tecnologia convencional (que é o oposto da tecnologia social). O quinto e último pressuposto decorrente dos anteriores, é que a produção de software livre por uma empresa estatal seria uma contradição, a menos que essa empresa tivesse mudado o seu processo de trabalho. A verificação dessa contradição foi o que conduziu ao objetivo geral da pesquisa.

Para alcançar esse objetivo foi realizado um levantamento da relação de softwares produzidos pelo Serpro no período entre 2003 - a instituição do Programa Serpro de Software Livre - e 2018 - o ano de conclusão da pesquisa, que coincidiu com o encerramento do programa. A partir dessa relação, foram identificados quais softwares eram livres e dentre eles um foi selecionado para estudo de caso. A análise da construção do software foi realizada sob a ótica da tecnologia social, com ênfase nas contribuições da Teoria Crítica da Tecnologia de Feenberg (2013).

Esta pesquisa foi desenvolvida dentro do Programa de Pós-Graduação em Tecnologia e Sociedade - PPGTE - da Universidade Tecnológica Federal do Paraná - UTFPR, dentro da linha de pesquisa Tecnologia e Trabalho e alinha-se com as temáticas "história da técnica e da tecnologia" e "produção e apropriação do conhecimento pelo trabalhador".

Uma pesquisa bibliográfica realizada em setembro de 2018 nas bases de periódicos Oasisbr, Scopus e Web of Science pelas combinações de palavras-chave "Software Livre + Tecnologia Social + Empresa Pública", "Software Livre + Tecnologia Social + Empresa Estatal" e "Free Software + Social Technology + State-owned enterprise" não encontrou resultados, sugerindo ineditismo da pesquisa ao abordar a produção de software livre em empresas estatais sob a perspectiva do software livre como uma tecnologia social.

\section{Fundamentação teórica}

Como fundamentos teóricos da produção de software foram utilizados Brooks (2009), Pressman e Maxim (2016) e Sommerville (2011), os quais contribuíram com o conceito de software e com as peculiaridades de sua produção. Sobre software livre, foram utilizadas as referências conceituais encontradas em Fogel (2017), o qual aborda a infraestrutura social, política e técnica de comunidades de software livre, Pacitti (2006), o qual aborda aspectos históricos e estratégicos do software livre, e Taurion (2004), o qual complementa as abordagens citadas com aspectos econômicos e empresariais.

A base de referências sobre economia solidária consistiu nos trabalhos de Singer (2002, 2004, 2013), Coraggio (2011, 2013, 2015) e Gaiger (2013, 2014, 2017), os quais contribuíram para o entendimento desse conceito no contexto latino-americano. Para 
tecnologia social foi utilizada essencialmente a obra de Dagnino (2010, 2014), o qual apresenta um marco analítico-conceitual abrangente sobre esse termo.

O embasamento teórico sobre métodos e técnicas de pesquisa utilizou as contribuições de Gil (2008), Marconi e Lakatos (2003) e Prodanov e Freitas (2013) para a elaboração do protocolo de pesquisa e de Martins (2008) e Yin (2010) para a metodologia específica de estudo de caso.

Ao longo da pesquisa bibliográfica foram identificadas algumas pontes conceituais relações entre pares de temas identificados pelas palavras-chave da pesquisa em obras de autores especialistas em um determinado tema. Coraggio (2015), Mance (2000), Singer (2004) e Stallman e Mance (2012) escrevem sobre conexões entre economia solidária e software livre. Triana (2014) escreve sobre o relacionamento entre software livre e tecnologia social. Pacitti (2006), Patriarca (2016) e Silveira (2006) abordam o software livre no contexto do Estado enquanto Komosinski (2014), Silva (2014) e Tiboni (2014) escrevem especificamente sobre software livre em empresas estatais.

A Figura 1 ilustra essas pontes e outras. Dagnino (2010, 2014) constrói declaradamente uma ponte entre a economia solidária e a tecnologia social, denominando a primeira como "uma plataforma cognitiva de lançamento" da segunda. Coraggio (2013) escreve sobre a relação entre a economia solidária e o Estado no contexto de uma economia mista, em que operam os setores público, empresarial capitalista e o popular. A Fundação Banco do Brasil (2018), uma organização mantida por empresa estatal, administra um banco de dados de tecnologias sociais que inclui um software livre, o Noosfero, o qual é a plataforma de uma rede social de empreendimentos de economia solidária, o Cirandas.NET. Essa rede social é estudada com profundidade na dissertação de Castro (2018).

Figura 1 - Pontes conceituais

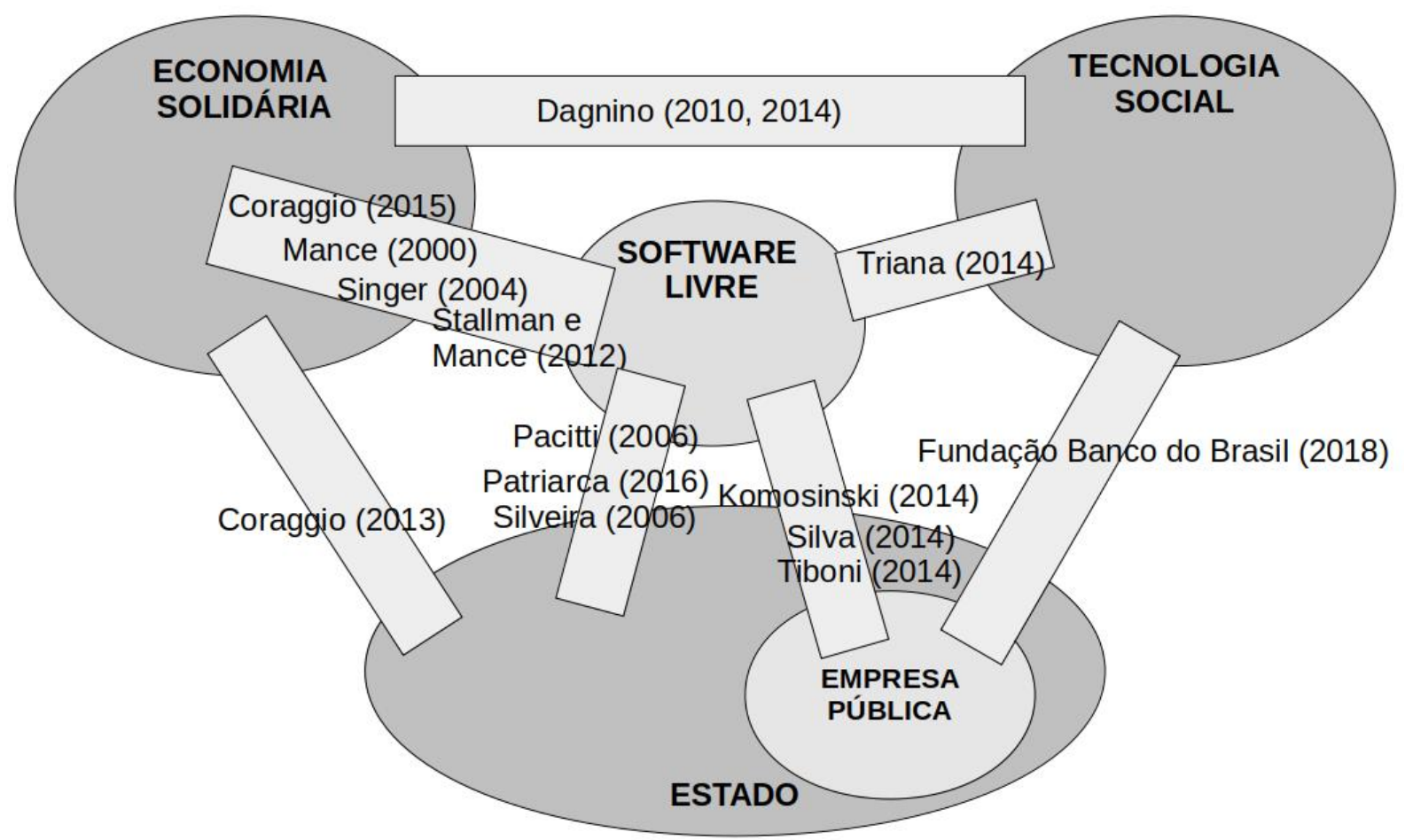

Fonte: autoria própria (2019) 


\section{Metodologia da pesquisa}

Esta pesquisa se caracterizou como exploratória, descritiva e qualitativa. Nesta pesquisa foram usados dados primários coletados a partir de um estudo de caso e dados secundários coletados a partir de pesquisa de documentos compilados ou redigidos por outros autores. O estudo de caso consiste de observação direta intensiva a partir de entrevistas com alguns funcionários do Serpro, orientadas por roteiros semiestruturados. Segundo Yin (2010, p. 39), o estudo de caso é um método apropriado quando se deseja "entender um fenômeno da vida real em profundidade", considerando que o entendimento englobe condições contextuais significativas. Por isso, o estudo de caso foi considerado o método mais apropriado para esta pesquisa.

A partir da escolha da metodologia de pesquisa e com base nos objetivos a serem atingidos, foi delineado o seguinte protocolo de pesquisa:

a) Identificar entre os softwares construídos pelo Serpro entre 2003 e 2018 aqueles que pudessem ser caracterizados como softwares livres, usando como referência a definição da Free Software Foundation, independente da classificação dada a eles pela empresa.

b) Selecionar um desses softwares para um estudo de caso;

c) Selecionar um modelo de referência organizacional de comunidade de software livre para comparar os processos de construção e manutenção;

d) Analisar o software escolhido, seus usuários e desenvolvedores.

Esse protocolo foi refinado em 5 macroetapas, ilustradas na Figura 2.

A pesquisa documental utilizou diversas fontes:

a) O sítio institucional do Serpro (http://www.serpro.gov.br);

b) Edições da revista TEMA (SERPRO, 2017) publicadas pelo Serpro entre 2003 e 2016 (ano da última edição disponível);

c) $\mathrm{O}$ Portal do Software Público Brasileiro - $\mathrm{SPB}$ (http://www.softwarepublico.gov.br);

d) O livro Software Livre: uma história de resistência, de Mazoni (2017), diretorpresidente da empresa entre 2007 e 2016;

e) Monografias de especialização lato-sensu de funcionários do Serpro desenvolvidas em Programa de Pós-graduação realizado em convênio com a Universidade Federal do Rio Grande do Sul - UFRGS;

f) O sistema eletrônico do serviço de informação ao cidadão - e-SIC (http://esic.cgu.gov.br).

Nos documentos obtidos a partir de pesquisa realizada pela ferramenta de busca do sítio corporativo do Serpro há menções a 2 softwares que, de acordo com a empresa, seriam livres: Demoiselle Framework e Expresso.

Nas edições da revista TEMA foram encontradas menções a 24 softwares que, de acordo com os textos dos artigos, receberam licenças livres ou foram construídos a partir de softwares livres, herdando por contaminação esse aspecto. Entretanto, foram encontradas informações sobre o código fonte para apenas 5 desses 24 softwares: AlienDroid, Expresso, Demoiselle Framework, Demonstra e Ouvidoria.

No Portal do Software Público Brasileiro, após cruzamento de dados com o portal do Sistema de Administração de Recursos de Tecnologia da Informação - SISP - foram encontrados 3 softwares de autoria do Serpro: Demoiselle Framework, Ouvidoria e Sagui. 
O livro de Mazoni (2017) menciona 4 softwares os quais identifica como livres: Demoiselle Framework, ExpressoV3 ou ExpressoBR, Participa.br e Sagui.

De 37 monografias produzidas por convênio entre Serpro e UFRGS, 4 abordam softwares que os autores afirmam terem sido desenvolvidos pela empresa e serem de licenciamento livre: Demoiselle Framework (KOMOSINSKI, 2014; SILVA, 2014; TIBONI, 2014), Expresso (KOMOSINSKI, 2014; SILVA, 2014; TIBONI, 2014), LianeTTS (SILVA, 2014), Ouvidoria (SILVA, 2014), Participa.br (SOUZA, 2014) e Sagui (SILVA, 2014).

Figura 2 - Diagrama das etapas da pesquisa

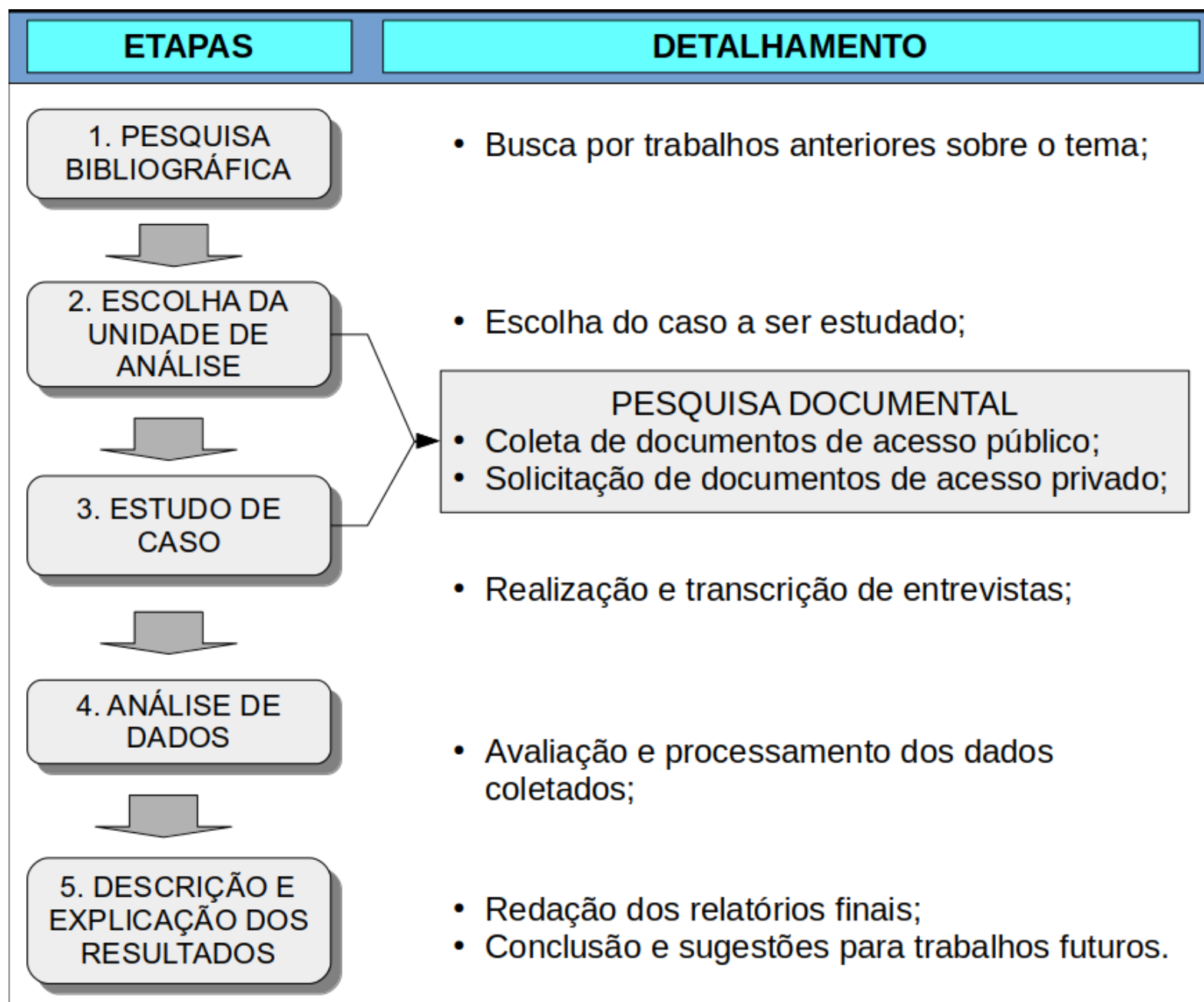

Baseado em Gil (2008, p. 31-32)

Fonte: autoria própria (2019)

A partir de solicitações ao sistema e-SIC, o Serpro informou oficialmente que produziu 840 softwares de código aberto no período entre 2003 e 2018 (BRASIL, 2017; BRASIL, 2018). O código aberto é condição necessária, mas não suficiente para que um software seja livre. Assim como para as demais fontes, foi necessário validar se os softwares eram livres, de acordo com o conceito da Free Software Foundation, usado como referência para a pesquisa. A partir desse conceito, foi criado um instrumento de validação com duas perguntas, denominado de Crivo de Stallman (Quadro 1). 
Para responder à pergunta CS1 do Crivo de Stallman, foram procurados os repositórios de código fonte dos softwares identificados como softwares livres ou de código aberto por cada uma das fontes documentais. Apenas 5 dos mais de 800 softwares pressupostamente de código aberto tinham o código fonte disponível de forma aberta: AlienDroid, Demoiselle Framework, Estaleiro, Expresso V3 e Sagui.

Quadro 1 - Crivo de Stallman

\begin{tabular}{|l|l|l|}
\hline $\begin{array}{l}\text { [CS1] O código-fonte está } \\
\text { disponível? }\end{array}$ & $\begin{array}{l}\text { [CS2] A licença restringe o uso, } \\
\text { execução ou modificação do } \\
\text { software? }\end{array}$ & O software é livre? \\
\hline Sim & Sim & Não \\
\hline Sim & Não & Sim \\
\hline Não & Sim & Não \\
\hline Não & Não & Não \\
\hline
\end{tabular}

Fonte: autoria própria (2019)

Após aplicar a segunda pergunta do Crivo, apenas 4 softwares puderam ser classificados como livres: AlienDroid (CARVALHO, 2019), Demoiselle Framework (SERPRO, 2019a), Expresso V3 (SERPRO, 2019c) e Sagui (BRASIL, 2019b). É importante destacar que para a Free Software Foundation, a ausência de licença equivale a uma licença que restringe a liberdade. Por isso, o Estaleiro (SERPRO, 2019b) foi eliminado, pois dois de seus componentes não possuíam licença quando seu repositório foi analisado.

Conforme as etapas planejadas para a pesquisa, uma vez definidos os softwares livres construídos pelo Serpro, era necessário selecionar um como unidade de análise para o estudo de caso. Demoiselle Framework e Expresso V3 foram eliminados para reduzir a possibilidade de influência de preconceitos, simpatias ou antipatias do pesquisador, o qual participou de seus projetos de desenvolvimento e manutenção. Essa postura baseia-se em observação de Prodanov e Freitas (2013, p. 152) sobre os requisitos para uma crítica adequada. Entre AlienDroid e Sagui, o segundo foi escolhido pela suposta relevância para a sociedade mencionada no Portal do Software Público Brasileiro (MINISTÉRIO DO PLANEJAMENTO, DESENVOLVIMENTO E GESTÃO, 2018) e por sua maior longevidade dentro do período analisado. Ao fazer parte do Portal do Software Público - PSP, o Sagui integra um conjunto de softwares para os quais é atribuída a qualidade de serem recursos benéficos para a sociedade, de acordo com a definição de software público constante no PSP. Na documentação do AlienDroid não há menção explícita sobre o benefício à sociedade como um dos objetivos do software.

Escolhida a unidade de análise, seguiu-se a realização da análise do software e dos atores envolvidos em seu uso e construção. Para o software foi realizada uma pesquisa documental mais específica e uma análise da estrutura de seu código fonte. Para os atores foi realizada uma pesquisa documental dos recursos de comunicação em comunidade e entrevistas com uma amostra dos envolvidos. Oficialmente, por meio do e-SIC, o Serpro informou que aproximadamente 100 empregados usavam o Sagui. Devido à estimativa de que haveria apenas um mês para realizar as entrevistas, considerando o prazo de aprovação do projeto no comitê de ética e o tempo necessário para transcrição das entrevistas, análise dos resultados e o prazo para a defesa da dissertação, foi estabelecida uma amostra de 7 empregados da empresa: 3 usuários (técnicos de suporte de rede), 1 desenvolvedor e 3 
gerentes ( 2 gerentes dos técnicos e 1 gerente do desenvolvedor). Para cada grupo foi elaborado um roteiro de entrevista semiestruturada com quatro questões que abordaram o perfil do empregado, sua participação na construção e manutenção do Sagui e seu envolvimento pessoal com a temática do software livre. Essas entrevistas foram realizadas entre setembro e dezembro de 2018. 2 usuários e 1 gerente foram entrevistados diretamente na unidade de Curitiba da empresa. Os demais foram entrevistados por telefone ou e-mail, devido ao fato de morarem e trabalharem em outras cidades (Fortaleza, Recife e Salvador).

\section{Análise de dados da pesquisa}

Sagui é o acrônimo de Sistema de Apoio à Gestão Unificada de Informações. Ele foi desenvolvido dentro do Serpro em 2004, sem a participação de outras organizações e foi usado para atender demandas internas. Um pouco mais tarde, ele teve seu código fonte aberto e recebeu uma licença livre (GPLv2, criada pela Free Software Foundation). O Sagui lida com atualização e correção em massa de estações de trabalho e servidores Linux (um sistema operacional de licença livre). O Sagui automatiza o trabalho de manutenção em estações de trabalho e servidores e substitui vários técnicos de suporte por uma única pessoa. Do ponto de vista da racionalização de recursos, é muito útil para uma empresa que tem entre 6 e 8 mil computadores com sistema Linux. O Sagui é um software com arquitetura distribuída ${ }^{1}$ (Figura $3)$.

Figura 3 - Visão geral da arquitetura do Sagui

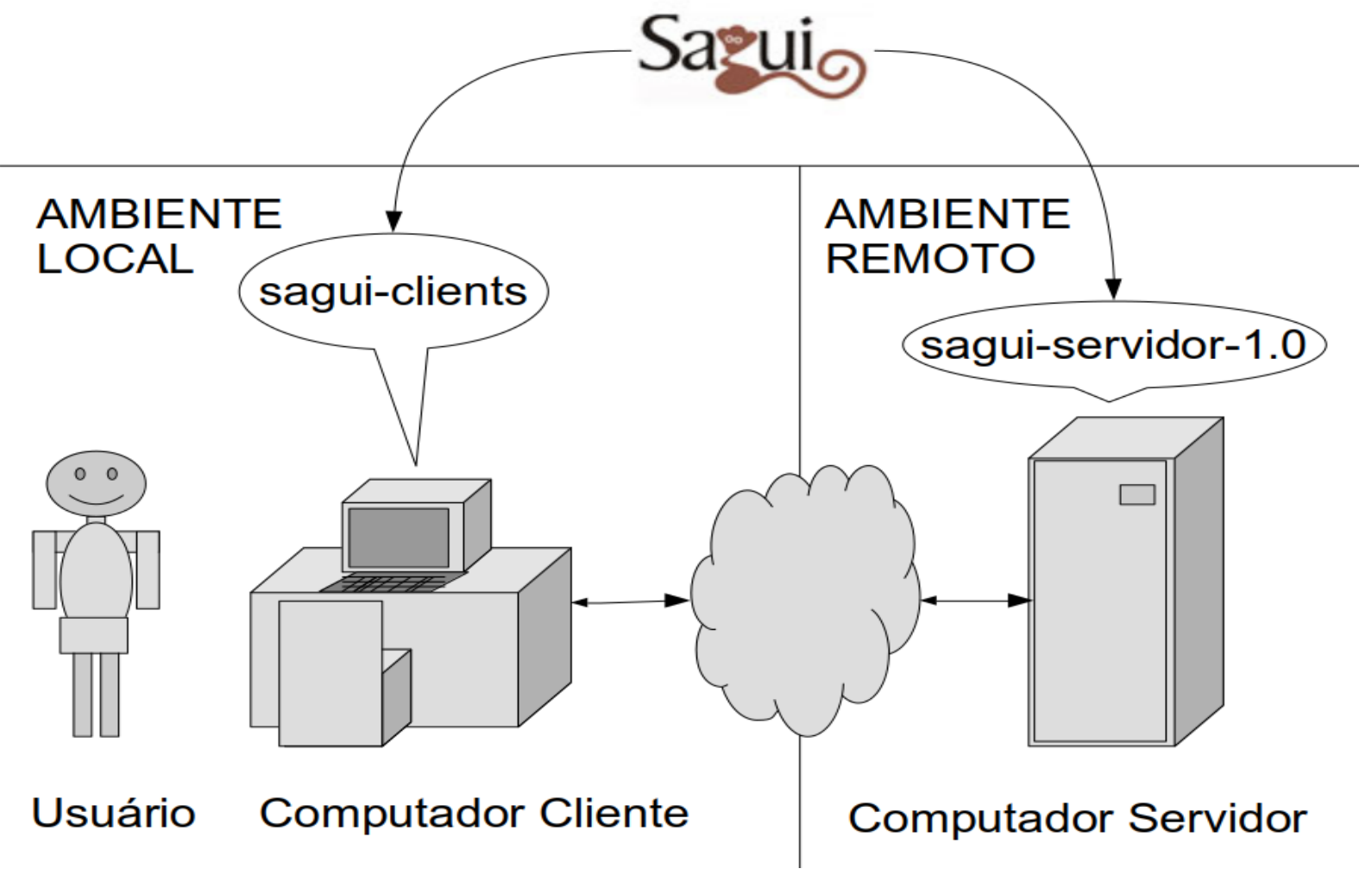

Fonte: autoria própria (2019)

1 Segundo Tanenbaum (2003, p. 18), "um sistema distribuído [é], um conjunto de computadores independentes [que] parece ser, para usuários, um único sistema coerente". 
Ele tem um componente cliente hospedado em cada estação de trabalho, que é um computador operado diretamente e com frequência por seres humanos, e em cada servidor, que é um computador que serve outros computadores. Esse componente cliente é escrito na linguagem shell script, parte do sistema operacional Linux. Sua outra parte é um componente servidor (hospedado em uma única máquina) escrito com a linguagem PHP, também um software livre. Uma análise realizada com a ferramenta pdepend, específica para a linguagem PHP, revelou que o componente servidor (que tem a maioria absoluta de instruções implementadas do software como um todo) tem uma complexidade ciclomática ${ }^{2}$ de 38 , a qual, de acordo com Pichler (2016) representa um software muito complexo.

De acordo com os técnicos de suporte, o Sagui é amplamente usado pela equipes de administração de redes de computadores do Serpro, mas está em declínio e a tendência é sua substituição pelo Ansible, também um software livre, lançado 8 anos após o Sagui, mas produzido por uma comunidade e não pelo Serpro. Os gerentes dos técnicos informaram, em entrevistas feitas pessoalmente e por e-mail, que o uso do Sagui é obrigatório para as equipes de administração de redes.

O desenvolvedor disse, em entrevista por telefone, que o Sagui foi um software inovador na época de sua criação, pois não existia nada parecido no mercado. Ele acrescentou que o Sagui sempre foi um projeto de um só homem, nunca teve um desenvolvimento colaborativo, foi pressionado a se tornar software livre e está atualmente obsoleto, mas não é substituível por um único software - incluindo Ansible.

Segundo o desenvolvedor, em entrevista por telefone, o Sagui não foi produzido de acordo com o processo padrão de desenvolvimento de software da empresa, o Processo Serpro de Desenvolvimento de Software - PSDS.

\footnotetext{
O objetivo do PSDS é fornecer um processo de software padronizado e dinâmico às suas equipes de desenvolvimento, que consolide as melhores práticas de desenvolvimento de software. O PSDS oferece a base para responder às perguntas: "quem faz o quê", "quando" e "como", no contexto de desenvolvimento e manutenção de soluções. Sua estrutura está baseada em macroatividades (disciplinas), um conjunto relacionado de atividades que podem ser referentes a: Negócio, Gestão de Processo, Gestão de Projetos, Engenharia ou Suporte. (PINHO, 2010, p. 99)
}

Segundo o gerente do desenvolvedor, os estudos sobre software livre no Serpro começaram em 1999. A partir desses estudos foi gerado um relatório que recomendou o uso de vários softwares livres em estações de trabalho e servidores, começando com o sistema operacional Linux. Assim, ocorreu uma larga instalação e migração de computadores do Serpro para Linux. A necessidade de atualizar e corrigir essas máquinas e a disponibilidade de um técnico de rede com conhecimento de desenvolvimento de software criaram o cenário para a construção do Sagui. 
O Sagui foi produzido dentro da diretoria de infraestrutura de tecnologia da informação do Serpro e não dentro da diretoria responsável pelo desenvolvimento de software. Ele foi produzido a partir de uma demanda interna e não seguiu o processo de desenvolvimento do Serpro para a entrega de software para clientes.

O Sagui, como ator não-humano, nunca constituiu uma comunidade de usuários e desenvolvedores ao redor de si. A observação dos dados obtidos mostrou que o Sagui se enquadra no que Taurion (2004) caracteriza como a realidade da maioria dos projetos de software livre: "Poucos projetos despertam interesse e atraem um número expressivo de voluntários. Muitos projetos são iniciativas isoladas e permanecem desta maneira até desaparecerem." (TAURION, 2004, p. 67)

O caso do Sagui serve para detalhar a intersecção entre os conceitos de economia solidária e software livre. Software, de acordo com Brooks (2009), pode ser mantido por um indivíduo ou por um coletivo. Para o segundo caso, temos um conjunto que podemos chamar de comunidade ou coletivo de software. A economia solidária encontra-se com o software livre quando há uma intersecção do software livre com o software comunitário ou coletivo. A Figura 4 serve para esclarecer isso ao posicionar o Sagui como um software livre mantido por um indivíduo, fora da intersecção contendo princípios da economia solidária.

Figura 4 - Intersecção entre software livre e software coletivo

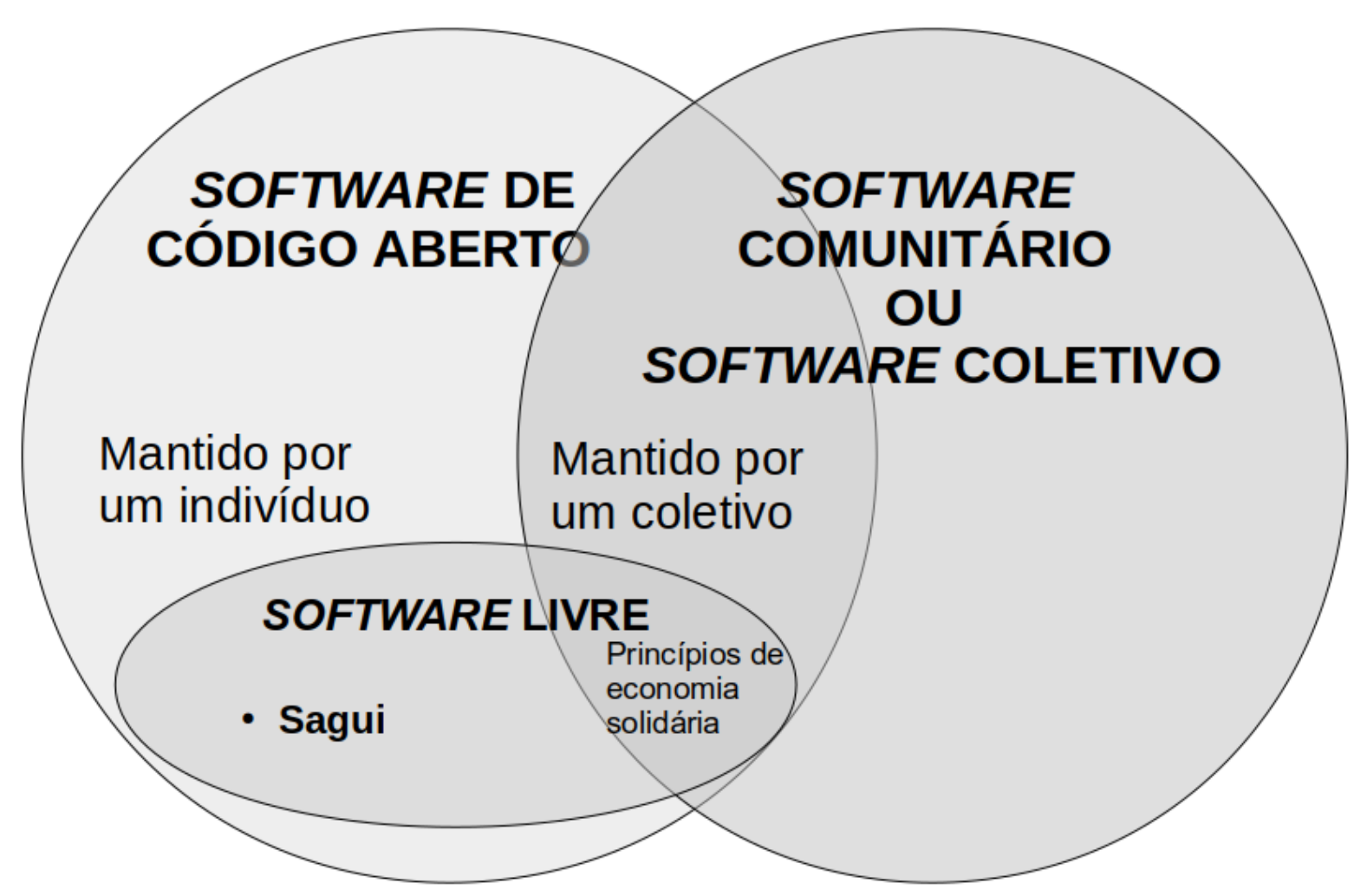

Fonte: autoria própria (2019)

\section{Considerações finais}

O Sagui nasceu como um software sem licença em 2004 e era uma ferramenta que atendia uma necessidade dentro do Serpro, não diretamente relacionada aos propósitos da organização. Sua criação foi o resultado de uma autonomia individual - um técnico de suporte 
a redes de computadores teve a iniciativa de desempenhar o papel de desenvolvedor de software e obteve apoio de seu gerente para isso. A conversão do Sagui em software livre não foi iniciativa do desenvolvedor nem do seu gerente, mas de uma instância superior na estrutura organizacional da empresa. Assim, o Sagui tornou-se software livre não em um movimento de baixo para cima, a partir de seus usuários e desenvolvedores, mas de cima para baixo, por decisão que seguiu a hierarquia de comando da organização. Em abril de 2008, ele foi hospedado no Portal do Software Público Brasileiro como um aparente benefício à sociedade. Entretanto, a sociedade não se apropriou do Sagui. Nenhuma comunidade se formou em torno do software. A autonomia individual não evoluiu para uma autonomia coletiva. Como software livre, o Sagui permaneceu como uma tecnologia social "potencial" somente uma promessa de inclusão social.

A revisão de literatura e os dados obtidos por esta pesquisa permitiram observar que quando comunidades de software livre estão organizadas sob uma democracia baseada em consenso (FOGEL, 2017), elas são similares a empreendimentos de economia solidária. Isso confirma de modo estrito o primeiro pressuposto da pesquisa.

Há similaridades entre as propriedades intrínsecas do software livre, de acordo com a Free Software Foundation, e o conceito de Dagnino (2010) de tecnologia social, como a adaptação a empreendimentos de pequeno tamanho e a liberação de potencial físico e financeiro e da criatividade do produtor direto. Triana (2014), entretanto, afirma que o software livre é uma tecnologia social somente quando se pode substituir "comunidade" por "população". Isso implica que uma comunidade é uma condição necessária para um software livre ser uma tecnologia social. Essa restrição também confirma estritamente o segundo pressuposto da pesquisa.

O processo padrão de desenvolvimento de software do Serpro - PSDS (PINHO, 2010) - parece estar aderente ao modo de produção capitalista, ao visar apenas controle para obter eficiência e produtividade. O Sagui, entretanto, não seguiu esse processo e não foi criado como um produto para um cliente da empresa. Assim, o Sagui não invalida o pressuposto de que a produção de software pelo Serpro é orientada pelo modo de produção capitalista.

O Sagui não tem todas as características de uma tecnologia convencional, mas, de acordo com o entendimento de Triana (2014) também não é uma tecnologia social "cinética", no sentido implícito de produzir inclusão social. Ao fim da pesquisa, o Sagui foi classificado como uma tecnologia social "potencial".

Não houve mudança no processo padrão de desenvolvimento de software do Serpro para a criação do Sagui. Conforme foi mencionado anteriormente, o PSDS nem mesmo foi usado para a criação do Sagui. O software foi produzido intersticialmente por uma área da empresa cujo propósito primário não é produzir software. Assim, o último pressuposto, o da contradição, não se verificou.

A partir do que foi estudado, em aspectos quantitativos, poucos softwares foram produzidos pelo Serpro com licenciamento livre, em comparação com sua produção total. Mesmo que os 840 softwares que a empresa afirma serem de código aberto tenham sido construídos com código livre, não podem ser considerados como softwares livres, de acordo com a definição estrita da Free Software Foundation. Mesmo que eles tenham sido compostos por outros softwares que têm licenças livres e seu código aberto em repositórios de livre acesso, se esses softwares produzidos pelo Serpro não têm seu código específico disponível em repositórios de acesso aberto com licenças que explicitamente os identifiquem como livres, eles não podem ser considerados softwares livres. 
As quatro liberdades do software livre não são características intrínsecas do software, mas características que se manifestam a partir de controle humano. Um humano tem de abrir o código fonte e adicionar uma licença para o software ser livre. Os valores do software livre dependem diretamente do controle humano. Um software, seja ele livre ou não, é um produto de tecnologia e segundo Feenberg (2013), a tecnologia é humanamente controlada e tem valores dos humanos que a constroem.

\section{Referências}

ABRANCHES, Sérgio Henrique. Questão da empresa estatal: economia, política e interesse público. Revista de Administração de Empresas, São Paulo, v. 19, n. 4, p. 95-105, Dez. 1979. Disponível em: http://www.scielo.br/scielo.php?script=sci_arttext\&pid=S0034$75901979000400009 \& \operatorname{lng}=e n \& n r m=i s o$. Acesso em 18 jun. 2017.

BIRKINBINE, Benjamin J. Free Software as Public Service in Brazil: An Assessment of Activism, Policy, and Technology. International journal of communication. 2016 v. 10 pp. 3893-3908. Disponível em: http://ijoc.org/index.php/ijoc/article/view/4974. Acesso em: 9 jul. 2017.

BRASIL. Histórico. 2014. Disponível em: https://www.governodigital.gov.br/sobre-oprograma/historico. Acesso em: 12 abr. 2018.

BRASIL. Catálogo de Software Público. Disponível em: https://softwarepublico.gov.br/social/search/software_infos. Acesso em: 12 out. 2019a.

BRASIL. Solicitação de dados sobre sistemas em código aberto e software livre para projeto de pesquisa. 24 de julho de 2017. Disponível em:

http://www.consultaesic.cgu.gov.br/busca/dados/Lists/Pedido/Item/displayifs.aspx?List=0c83 9f31\%2D47d7\%2D4485\%2Dab65\%2Dab0cee9cf8fe \&ID=579124\&Web=88cc5f44\%2D8cfe \%2D4964\%2D8ff4\%2D376b5ebb3bef. Acesso em: 12 out. 2019.

BRASIL. Esclarecimento sobre projetos de código aberto desenvolvidos entre 2003 e 2016. 2 de abril de 2018. Disponível em: http://www.consultaesic.cgu.gov.br/busca/dados/Lists/Pedido/Item/displayifs.aspx?List=0c83 9f31\%2D47d7\%2D4485\%2Dab65\%2Dab0cee9cf8fe\&ID=643314\&Web=88cc5f44\%2D8cfe \%2D4964\%2D8ff4\%2D376b5ebb3bef. Acesso em: 12 out. 2019.

BRASIL. Sagui. Disponível em: https://softwarepublico.gov.br/gitlab/groups/sagui. Acesso em: 12 out. $2019 b$.

BROOKS, Frederick Phillips. O mítico homem-mês: ensaios sobre engenharia de software. Tradução: César Brod. Rio de Janeiro: Elsevier, 2009.

CARVALHO, Marlon. AlienDroid: Persistência de Objetos em Android. Disponível em: https://github.com/marloncarvalho/aliendroid-activerecord. Acesso em: 12 out. 2019.

CASTELLS, Manuel. A sociedade em rede. 8.ed. São Paulo: Paz e Terra, 2005.

CASTRO, Diego Palma de. Economia solidária e tecnologia social: a apropriação pelos trabalhadores de empreendimentos econômicos solidários do Cirandas.net. 2018. Dissertação 
(Mestrado em Tecnologia e Sociedade) - Programa de Pós-Graduação em Tecnologia e Sociedade, Universidade Tecnológica Federal do Paraná, Curitiba, 2018. Disponível em: http://repositorio.utfpr.edu.br/jspui/handle/1/3846. Acesso em: 6 mai. 2019.

CORAGGIO, José Luis. Economía social y solidaria: El trabajo antes que el capital. QuitoEcuador: 1era. Edición Ediciones Abya-Yala, 2011.

CORAGGIO, José Luis. La economía social y solidaria, y el papel de la economía popular en la estructura económica. Tercer Seminario Internacional: "Rol de la Economía Popular y Solidaria y su aporte en el Sistema Económico Social y Solidario". Quito, 2013. p. 21-46. Disponível em:

http://www.coraggioeconomia.org/jlc/archivos\%20para\%20descargar/La\%20economia\%20P opular\%20y\%20Solidaria\%20El\%20Ser\%20Humano\%20Sobre\%20el\%20Capital-1.pdf. Acesso em: 24 jan. 2018.

CORAGGIO, José Luis. Propuesta pionera: El potencial de un Ministerio de Economia Popular. Página 12, Argentina, 13 de setembro de 2015. Disponível em: https://www.pagina12.com.ar/imprimir/diario/suplementos/cash/17-8789-2015-09-13.html. Acesso em: 24 jan. 2018.

DAGNINO, Renato. Tecnologia social: ferramenta para construir outra sociedade. 2. ed. Campinas, SP: Komedi, 2010.

DAGNINO, Renato. Tecnologia social: contribuições conceituais e metodológicas. Campina Grande, PB; Florianópolis, SC: Ed. Insular, 2014.

FEENBERG, Andrew. O que é a Filosofia da Tecnologia? In: NEDER, Ricardo T. (Org). Andrew Feenberg: racionalização democrática, poder e tecnologia. 2. ed. Brasília. Observatório do Movimento pela Tecnologia Social na América Latina/Centro de Desenvolvimento Sustentável / CDS / UnB / Capes, 2013. p. 51-65.

FOGEL, Karl. Producing Open Source Software: How to Run a Successful Free Software Project. 2.ed. 2017. Disponível em: http://producingoss.com/en/producingoss.pdf. Acesso em: 17 fev. 2016.

FREE SOFTWARE FOUNDATION. O que é o software livre? 2001. Disponível em: https://www.gnu.org/philosophy/free-sw.pt-br.html. Acesso em: 12 abr. 2018.

FUNDAÇÃO BANCO DO BRASIL. Banco de Tecnologias Sociais. Disponível em: http://tecnologiasocial.fbb.org.br/tecnologiasocial/principal.htm. Acesso em: 15 fev. 2018.

GAIGER, Luiz Inácio. A economia solidária e a revitalização do paradigma cooperativo. Revista Brasileira de Ciências Sociais, v. 28, n. 82, jun. 2013. Disponível em: <www.scielo.br/pdf/rbcsoc/v28n82/v28n82a13.pdf>. Acesso em: 24 jan. 2018.

GAIGER, Luiz Inácio. A economia solidária e a ativação dos vínculos sociais. XVIII Congresso Brasileiro de Sociologia. 23 a 29 de julho de 2017. Brasília. Anais Eletrônicos... Disponível em: <sbs2017.com.br/anais/resumos/PDF-eposter-trab-aceito-1128-1.pdf>. Acesso em: 24 jan. 2018. 
GAIGER, Luiz Inácio G. (Coord.) KUYVEN, Patrícia Sorgatto. OGANDO, Cláudio Barcelos, KAPPES, Sylvio Antonio. SILVA, Jardel Knecht da. A economia solidária no Brasil: uma análise de dados nacionais. São Leopoldo: Oikos, 2014.

GIL, Antonio Carlos. Métodos e técnicas de pesquisa social. 6. ed. São Paulo: Atlas, 2008.

KOMOSINSKI, Luciano. A relação do software livre com os sistemas estruturadores do Serpro. 2014. Trabalho de conclusão (Especialização em Gestão Pública), Escola de Administração, Universidade Federal do Rio Grande do Sul, Porto Alegre, 2014. Disponível em: http://www.lume.ufrgs.br/handle/10183/127287. Acesso em: 11 jul 2016.

LIMA, Leonardo Santos de. Cultura do software livre e desenvolvimento: Uma análise sobre potencialidades e limites diante e adiante da "nova economia". Revista Crítica de Ciências Sociais, 102, Dez. 2013: 71-78, Centro de Estudos Sociais da Universidade de Coimbra. Artigo. Disponível em: http://rccs.revues.org/pdf/5462. Acesso em: 23 fev. 2017.

MANCE, Euclides André. Economia Solidária: um novo paradigma? Instituto de Filosofia da Libertação. Maio de 2000b. Disponível em: http://euclidesmance.net/docs/economia2.htm. Acesso em: 16 nov. 2018.

MARCONI, Marina de Andrade. LAKATOS, Eva Maria. Fundamentos de metodologia científica. 5.ed. São Paulo : Atlas, 2003.

MARTINS, Gilberto Andrade. Estudo de caso: uma reflexão sobre a aplicabilidade em pesquisas no Brasil. Revista de Contabilidade e Organizações: RCO, FEARP/USP, v. 2, n. 2, p. 8 - 18 jan./abr. 2008. Disponível em:

http://www.revistas.usp.br/rco/article/view/34702/37440. Acesso em: 14 abr. 2018.

MAZONI, Marcos. Software livre - uma história de resistência. Porto Alegre: Renascença, 2017.

MCCABE, Thomas J. A Complexity Measure. IEE Transactions on Software Engineering, n. 4, v. 2, dez. 1976. Disponível em: http://www.literateprogramming.com/mccabe.pdf. Acesso em: 3 dez. 2018.

MILANO, Mariana Tonussi. A construção social do mercado colaborativo de software livre durante o Governo Lula: agentes, estratégias e discursos. 2015. Tese (Doutorado em Ciências Sociais) - Faculdade de Ciências e Letras, Universidade Estadual Paulista, Araraquara, 2016. Disponível em: <http://repositorio.unesp.br/handle/11449/139468>. Acesso em: 11 jul. 2016.

MINISTÉRIO DO PLANEJAMENTO, DESENVOLVIMENTO E GESTÃO. Software Público Brasileiro. Disponível em: https://softwarepublico.gov.br/social/. Acesso em: 7 mai. 2019.

PACITTI, Tércio. Paradigmas do software aberto. Rio de Janeiro: LTC, 2006.

PATRIARCA, Joaquim Antonio Saraiva. O Software Livre e de Código Aberto na Administração Pública - Dos mitos às questões de natureza legal, ética e de optimizações de recursos públicos. 2016. Dissertação (Mestrado em Tecnologias de Informação Geográfica - 
Ambiente e Ordenamento de Território) - Faculdade de Letras, Universidade de Coimbra, Coimbra, 2016. Disponível em: https://estudogeral.sib.uc.pt/handle/10316/30768. Acesso em: 11 jul. 2017.

PICHLER, Manuel. Cyclomatic Complexity. 7 jan. 2016. Disponível em:

https://pdepend.org/documentation/software-metrics/cyclomatic-complexity.html. Acesso em: 29 nov. 2018.

PINHO, Viviane Malheiros. Uma contribuição para a melhoria colaborativa e distribuída de processos de software. 2010. Tese (Doutorado em Ciências de Computação e Matemática Computacional) - Instituto de Ciências Matemáticas e de Computação, Universidade de São Paulo, São Carlos, 2010. Disponível em:

http://www.teses.usp.br/teses/disponiveis/55/55134/tde-18082010-143052. Acesso em: 11 dez. 2018.

PRESSMAN, Roger S. MAXIM, Bruce R. Engenharia de software: uma abordagem profissional. 8. ed. Porto Alegre: AMGH, 2016.

PRODANOV, Cleber Cristiano. FREITAS, Ernani Cesar de. Metodologia do trabalho científico: métodos e técnicas de pesquisa e do trabalho acadêmico. 2. ed. Novo Hamburgo: Feevale, 2013.

ORAM, Andy. Open Source in Brazil. Sebastopol, Califórnia, Estados Unidos da América: O’Reilly Media, 2016.

SERPRO. Demoiselle. Serviço Federal de Processamento de Dados. [2019a]. Disponível em: https://github.com/demoiselle. Acesso em: 12 out. 2019.

SERPRO. Estaleiro. Serviço Federal de Processamento de Dados. [2019b] Disponível em: https://github.com/estaleiro. Acesso em: 12 out. 2019.

SERPRO. Expresso. Serviço Federal de Processamento de Dados. [2019c] Disponível em: https://gitlab.com/expresso_livre/Expresso. Acesso em: 12 out. 2019.

SERPRO. Revista TEMA. Disponível em: <http://www.serpro.gov.br/tema> Acesso em: 29 dez. 2017.

SINGER, Paul. Desenvolvimento capitalista e desenvolvimento solidário. Estudos Avançados, São Paulo, v. 18, n. 51, pp. 7-22. 2004. Disponível em: http://www.scielo.br/pdf/ea/v18n51/a01v1851.pdf. Acesso em: 11 jul. 2017.

SINGER, Paul. Introdução à Economia Solidária. São Paulo: Fundação Perseu Abramo, 2002.

SINGER, Paul. La economía solidaria en Brasil. Tercer Seminario Internacional: Rol de la Economía Popular y Solidaria y su aporte en el Sistema Económico Social y Solidario. Quito, 2013. p. 21-46. Disponível em:

http://www.coraggioeconomia.org/jlc/archivos\%20para\%20descargar/La\%20economia\%20P opular\%20y\%20Solidaria\%20El\%20Ser\%20Humano\%20Sobre\%20el\%20Capital-1.pdf.

Acesso em: 24 jan. 2018. 
SILVA, Guilherme Funchal da. Estudo de caso do Projeto Expresso: a implantação de políticas públicas voltadas ao software livre. 2014. Trabalho de conclusão (Especialização em Gestão Pública), Escola de Administração, Universidade Federal do Rio Grande do Sul, Porto Alegre, 2014. Disponível em: http://www.lume.ufrgs.br/handle/10183/127295. Acesso em: 11 jul. 2016.

SILVEIRA, Sérgio Amadeu da. Propriedade Intelectual, Monopólios do Conhecimento e Software Livre. In: CARVALHO, Isamir Machado de. MENDES, Sérgio Peixoto e VERAS, Vivianne Muniz. Gestão do conhecimento: uma estratégia empresarial. Brasília : J.J. Gráfica e Comunicação, 2006.

SOMMERVILLE, Ian. Engenharia de Software. 9. ed. Tradução: Ivan Bosnic e Kalinka G. de O. Gonçalves. São Paulo. Pearson Prentice Hall, 2011.

SOUZA, Vanderlei de Menezes. Plataforma Participa.BR: um estudo sobre a participação social na formação das políticas públicas. 2014. Trabalho de conclusão (Especialização em Gestão Pública), Escola de Administração, Universidade Federal do Rio Grande do Sul, Porto Alegre, 2014. Disponível em: https://www.lume.ufrgs.br/handle/10183/127403. Acesso em: 13 jan. 2018.

STALLMAN, Richard. MANCE, Euclides. Declaração Pessoal de Richard Stallman e Euclides Mance. Curitiba. 15 de dezembro de 2012. Disponível em: https://stallman.org/solidarity-economy.pt.html. Acesso em: 13 fev. 2018.

TANENBAUM, Andrew S. Redes de Computadores. 4. ed. Rio de Janeiro: Campus, 2003.

TAURION, Cezar. Software livre: potencialidades e modelos de negócio. Rio de Janeiro: Brasport, 2004.

TIBONI, Antonio. Software livre como política de governo. 2014. Trabalho de conclusão (Especialização em Gestão Pública), Escola de Administração, Universidade Federal do Rio Grande do Sul, Porto Alegre, 2014. Disponível em:

http://www.lume.ufrgs.br/handle/10183/127438. Acesso em: 11 jul. 2016.

TRIANA, Yago Quiñones. Tecnologias sociais na era da informação: o caso das redes de software livre. Revista Contraponto, vol. 1, n. 1. jan/jul 2014. Disponível em: http://seer.ufrgs.br/index.php/contraponto/article/view/46230. Acesso em: 12 fev. 2018.

YIN, Robert K. Estudo de caso: planejamento e métodos. 4. ed. Porto Alegre: Bookman, 2010.

Recebido em maio de 2019.

Aprovado em outubro de 2019. 